\title{
Smart Waste Collection System based on loT (Internet of Things): A Survey
}

\author{
Shashank Shukla \\ M.Tech. IV Sem (CTA) \\ Department of CSE, G.G.C.T. \\ Jabalpur, India
}

\author{
Neeraj Shukla, PhD \\ Vice Principal, G.G.C.T. \\ Department of CSE, G.G.C.T. \\ Jabalpur, India
}

\begin{abstract}
As the population is increasing day by day, the environment should be clean and hygienic. In most of the cities the overflowed garbage bins are creating an unhygienic environment. This will further lead to the arise of different types of diseases. This will degrade the standard of living. To overcome these situations an efficient smart waste collection system has to be developed. As the scope of IoT is developing day by day effective methods can be found out easily. Various designs were proposed and have advantages as well as disadvantages. This paper is a survey based on Smart Waste Collection System based on IoT.
\end{abstract}

\section{Keywords}

GIS, RFID, LED

\section{INTRODUCTION}

We are currently experiencing a fast development of Smart Cities where Cities around the world are on the run to become smarter, but due to this development the quantity of waste \& garbage is increases day by day. Garbage management is becoming a global problem. Due to the lack of care and attention by the authorities the garbage bins are mostly seem to be overflowing It has to be taken into care by corresponding authorities and should think what method can be followed to overcome this.

\section{DIFFERENT APPROACHES}

The garbage management in cities has to be effectively and efficiently implemented. The various proposals were put forward and some of them already implemented. But it cannot be considered as an effective one. So a survey was done among different proposals and this survey paper includes survey among different methods for Waste Collection System based on IoT

The paper [1] proposed waste collection system is based on waste level data from trashcans in a metropolitan area. The data collected by sensors is sent over the Internet to a server where it is stored and processed. He collected data is then used for monitoring and optimizing the daily selection of trashcans to be collected, calculating the routes accordingly. Every day, the workers receive the newly calculated routes in their navigation devices. The key feature of this system is that it is designed to learn from experience and to make decisions not only on the daily waste level status but also on future state forecast, traffic congestion, balanced cost-efficiency functions, and other affecting factors that a priori humans cannot foresee. The rate at which trashcans are being filled can be analyzed based on historical data and the overflow predicted before it occurs. The optimized selection of trashcans to be collected is expected to reduce costs, improve collection efficiency or both, depending on predefined economic requirements. Fig. 1 shows the system overview.

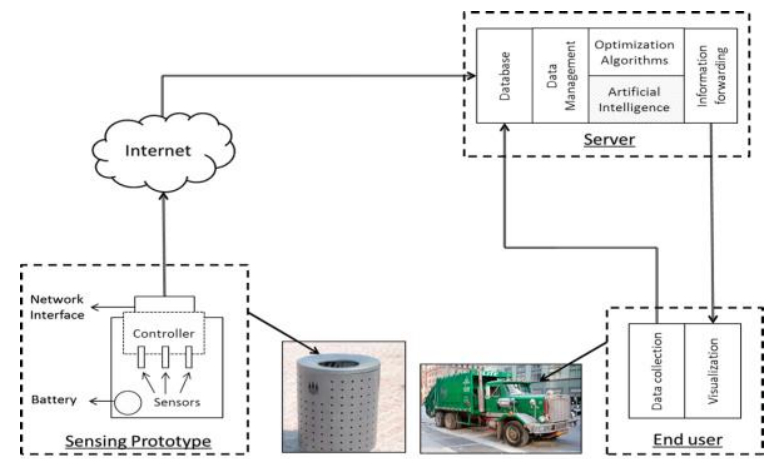

Fig. 1 system overview

Another method [2], there are multiple dustbins located throughout the city or the Campus, these dustbins are provided with low cost embedded device which helps in tracking the level of the garbage bins and a unique ID will be provided for every dustbin in the city so that it is easy to identify which garbage bin is full. The project module is divided into two parts Transmitter section and receiver section. Here in the transmitter section we are using 8051 microcontrollers, RF Transmitter and sensors these are attached to the dustbin. Where sensor is used to detect the level in the dustbin whether the dustbin is full or empty. The sensor senses the content of the dustbin and sends the signals or the data to the 8051 microcontroller, Power Supply $+9 \mathrm{~V}$ Battery power supply is given to the 8051 microcontroller to drive the system and the 8051 microcontroller reads the data from the sensor and process the data received from sensor, and the same data wirelessly transmitted to the Central system (Intel Galileo microcontroller) using RF Transmitted. RF Transmitter is to transmit the signal form 8051 microcontroller to the Intel Galileo microcontroller. Here RF Receiver is used to receive the data sent by RF transmitter to the Intel Galileo microcontroller. The Intel Galileo Gen2 Microcontroller is used to receive the data sent by the multiple transmitters and process the data and the same data transmitted to the Client i.e., Web Browser. But comparatively the number of components used is more such as 8051 microcontrollers, IR sensors that make an excessive cost and complex codes.

Another method [3] is that, Once the garbage reaches the threshold level ultrasonic sensor will trigger the GSM modem which will continuously alert the required authority until the garbage in the dustbin is squashed. Once the dustbin is squashed, people can reuse the dustbin. At regular intervals dustbin will be squashed. In this method, GSM 900A modem is used to send the messages. It consists of a GSM/GPRS modem with standard communication interfaces like RS-232 (Serial Port), USB, so that it can be easily connected to the other devices. The ultrasonic sensor is used to find the height 
of garbage filled at different intervals of time. They use three sensors at various heights like $h / 3,2 h / 3$ and $h$, where $h$ is the height of the bin but to make it affordable and to achieve the same results, only one sensor is placed at surface level. This system has various features such as durability, affordability, prevention against damage and maintenance issues. But they require a more amount of machines and labors.

Another method for garbage management is introduced [4] as follows. A dustbin is interfaced with microcontroller based system having IR wireless systems along with central system showing current status of garbage, on mobile web browser with html page by Wi-Fi. Hence the status will be updated on to the html page. There by to reduce human resources and efforts along with the enhancement of a smart city vision. Considering the need of modern technology, the smart garbage bin can expensive but considering the amount of dustbin needed in India, there for they used based sensors to reduce its cost and also make it efficient in applications. And at the sender side they used only a Wi-Fi module to send and receive data. But because of the use of weight sensor for detection of amount of garbage in dustbin. It will only detect the weight of waste; not how much level it is of. The message can be sent directly to the cleaning vehicle instead of the contractor's office. Thus garbage bins are managed. A Geographical Information System (GIS) transportation model for solid waste collection that elaborates plans for waste storage, collection and disposal has been proposed in for the city of Aansol in India. An enhanced routing and scheduling waste collection model is proposed for the Eastern Finland, featuring the usage of a guided variable neighborhood thresholding met heuristic. The aim of the research was to develop an optimal schedule for trucks on defined collection routes. The data from the bins are processed in the DSS and if it is correct it is sent to organizers of waste collection in this particular place and to the road police. The truck driver doesn't waste time for waiting, he/she goes to the next point and the route is dynamically recounted. When the problem is solved the system recounts the route for one of the available trucks and the waste from unlocked bin is collected. It is combined with dynamic routing algorithms to maximize the efficiency of waste collection.

In paper [5] Infrared sensor (IR sensor) is used which is a multipurpose sensor, which can detect the level of garbage. IR sensor emits the light, which is invisible to naked eye but the electronic components can detect it. It consists of IR transmitter and IR receiver. The output of IR sensor is acquired by The National Instruments myRIO-1900. It is an input output device which is portable and reconfigurable. USB acts as a connector between the NI myRIO-1900 and host computer. It has connectors $\mathrm{A}$ and $\mathrm{B}$ that acts as an expansion port and a connector $\mathrm{C}$ that act as a mini-system port, they carry the signals and these signals are distinguished by different connector names. Sensor senses level of the bin. The GUI gives the output of what level of garbage is filled. Sensor senses level of the bin. The graphical representation to access the output of the sensor is as shown below. It gives the output of what level of garbage is filled. When the level in a bin is reached the threshold, the LED placed at the location of the bin starts blinking. When the blinking LED is clicked, a display opens showing the location of the bin, status of the bin, data and time when the bin gets filled, mobile number and the text to send to the concerned person. But this system does not ensure whether garbage is cleaned or not and transportation cost is another issue.
In Paper [6] System monitors the garbage bins and informs about the level of garbage collected in the garbage bins via a web page. For this the system uses ultrasonic sensors placed over the bins to detect the garbage level and compare it with the garbage bins depth. The system makes use of AVR family microcontroller, LCD screen, Wi-Fi modem for sending data and a buzzer. The system is powered by a $12 \mathrm{~V}$ transformer. The LCD screen is used to display the status of the level of garbage collected in the bins. Whereas a web page is built to show the status to the user monitoring it. The web page gives a graphical view of the garbage bins and highlights the garbage collected in color in order to show the level of garbage collected. The LCD screen shows the status of the garbage level. The system puts on the buzzer when the level of garbage collected crosses the set limit. Thus this system helps to keep the city clean by informing about the garbage levels of the bins by providing graphical image of the bins via a web page.

In paper [7], A Geographical Information System (GIS) transportation model for solid waste collection that elaborates plans for waste storage, collection and disposal has been proposed in [7] for the city of Asansol in India. An enhanced routing and scheduling waste collection model is proposed for the Eastern Finland, featuring the usage of a guided variable neighborhood thresholding met heuristic. The aim of the research was to develop an optimal schedule for trucks on defined collection routes. The data from the bins are processed in the DSS and if it is correct it is sent to organizers of waste collection in this particular place and to the road police. The truck driver doesn't waste time for waiting, he/she goes to the next point and the route is dynamically recounted. When the problem is solved the system recounts the route for one of the available trucks and the waste from unlocked bin is collected. It is combined with dynamic routing algorithms to maximize the efficiency of waste collection.

In paper [8] assures the cleaning of dustbins soon when the garbage level reaches its maximum. In his management system IOT as the working in the field for networked radiofrequency identification (RFID), tracking the collection vehicle, Dustbin monitoring and other emerging sensing technologies. The IR sensor is act as level detector. The assures a low budget by changing all light traffic servers into Raspberry Pi. The sensor senses the content of the dustbin and sends the signals or the data to the ARM microcontroller then the microcontroller reads the data from the sensor and process the data received from sensor, and the same data will send to Dashboard section and this section send mail/message to respective Municipal / Government authority person or collection vehicle. If the dustbin is not cleaned in specific time, then the record is sent to the higher authority who can take appropriate action against the concerned contractor. This system also helps to monitor the fake reports and hence can reduce the corruption in the overall management system. This reduces the total number of trips of garbage collection vehicle and hence reduces the overall expenditure associated with the garbage collection.

\section{CONCLUSION}

This survey has been performed for collecting the details of Smart Waste Collection System based on IoT and to find out effective methods which are useful for providing hygiene environment in cities. As the level of garbage in the bins crossed the threshold, it will be informed to the corresponding authority, if it was found ignored then the details will be forwarded to the higher authority to take necessary actions. Thus a hygiene and clean environment can be provided. This 
survey helps in identifying all possible smart waste collection methods that can be implemented to make city clean.

\section{REFERENCES}

[1] Jose M. Gutierrez, Smart Waste Collection System Based on Location Intelligence. Procedia Computer Science 61 ( 2015 ) 120 - 127.

[2] Parkash, Prabu, IoT Based Waste Management for Smart City. IJECS Vol. 4, Issue 02 February 2016.

[3] Monika K, Smart Dustbin-An Efficient Garbage Monitoring System. IJECS Volume 6 Issue No. 06 June 2016.
[4] S.S. Navghane, IoT Based Garbage and Waste Collection Bin. IJARECE Volume 5, Issue 5, May 2016.

[5] Meghana K C, Dr. K R Nataraj IOT Based Intelligent Bin for Smart Cities. IJRITCC May 2016.

[6] Abdul Atif Khan, STUDY OF SMART CITY USING INTERNET OF THINGS. IJRITCC March 2016.

[7] Ghose, M.K., Dikshit,A GIS based transportation model for solid waste disposal - A case study on Asansol municipality. Journal of Waste Management.

[8] Vishesh Kumar Kurrel, Smart Garbage Collection Bin Overflows Indicator using Internet of Things. Volume 3, Issue 05 May 2016. 